\title{
O jogo equívoco das identidades
}

\author{
Barbeitos, Arlindo. Angola-Portugal: Representações de Si e de Outrem ou o Jogo Equívoco \\ das Identidades. Luanda: Kilombelombe, 20II. 843 p.
}

\section{Ermelinda Liberato"}

Resenhar um livro com essa densidade e pormenorização é tão difícil quanto traçar o perfil do autor pois este assume diversas facetas: o intelectual, o professor, o investigador, o nacionalista, o politico, o cidadão, que se resume numa única característica: o profissional. E é com profissionalismo, mas igualmente com muito empenho, dedicação e persistência que Arlindo Barbeitos escreveu a presente obra, pois de outro modo não seria possível empreender essa tarefa com tal densidade de pormenorização. Abordar temas ainda muito sensíveis para a sociedade angolana e portuguesa, como a raça, a miscigenação e todas as conotações daí resultantes, analisar obras essencialmente portuguesas, mas que representam os angolanos da altura (período colonial), parece-nos à partida, uma missão inglória, na medida em que se torna fundamental ter um excelente domínio da história dos dois países, assim como da relação entre os diferentes acontecimentos ocorridos nos dois lados do Atlântico.

Para melhor organização não só das suas ideias, mas sobretudo, para melhor compreensão do tema por parte do leitor, o autor dividiu a obra em 5 capítulos, todos eles extensos e muito descritivos. Cada um dos capítulos aborda especificamente determinado período da colonização e, é a transição de uma fase para a outra que desperta a atenção do autor, na medida em que são estas alterações que conduzem a uma mudança de direção da política colonial em si e que consequentemente afetam a vida dos angolanos no geral. Deste modo, e tomando como ponto de partida figuras emblemáticas representativas dessa política, o autor caracteriza toda a época colonial, com destaque para o período de intensificação da política colonial portuguesa, ou seja, de meados do século XIX até ao término da ditadura

\footnotetext{
"Professora auxiliar da Faculdade de Ciências Sociais da Universidade Agostinho Neto (FCS-UAN) LuandaAngola, doutora em Estudos Africanos, em 20I3, pelo Instituto Universitário de Lisboa (ISCTE-IUL), em Portugal, e pesquisadora do Centro de Estudos Internacionais do ISCTE (CEI-IUL) em Lisboa.
} 
salazarista no dia 25 de abril de 1974. Centrado em temáticas como colonização, política colonial, darwinismo social, raça, etnia, identidade, pátria, povo, nação, entre outras, a obra não procura ser acusatória ou mesmo justificar os diferentes acontecimentos, mas sim ser mais um contributo para o conhecimento não só da história dos dois países, mas sobretudo do relacionamento entre africanos e europeus, bem como do surgimento dos mestiços.

O ponto de partida do autor é explicado logo na introdução "vou tratar das representações que os portugueses, quer na Europa, quer em Angola, produziam acerca dos negros e depois dos mestiços, ao longo de 4 séculos... bem como as representações que os portugueses produziam de si próprios” (p. 29). Para alcançar os seus objetivos o autor assenta toda a sua investigação numa extensa bibliografia constituída por fontes arquivísticas, impressas, relatórios, documentos, crónicas, testemunhos, relatos de viagem, correspondência, textos literários, estudos relativos ao espaço colonial, estudos de natureza metodológica e teórica, bem como documentação fotográfica. Tão vasto campo de fontes de informação só poderia resultar em mais de Ioo páginas de bibliografia. Por outro lado, e como o próprio assume "como sujeito vivo, aleatório, insuficiente, vacilante, modesto, que introduz a sua própria finitude numa investigação que muito deve à sua biografia e experiência" (p. 32), o autor recorre a sua experiência enquanto testemunha para dar voz a alguns acontecimentos.

Barbeitos dá assim início ao seu trabalho, apresentando António de Oliveira Cadornega, autor da obra História das Guerras Coloniais Angolanas, e que se dedicou a conhecer "quer os começos da intervenção portuguesa em Angola, quer os povos africanos que habitavam a região e as suas respostas a esta presença estrangeira" (p. 39). Assim, a partir da sua obra, ficamos a conhecer melhor os acontecimentos que marcaram os séculos XVI e XVII, que corresponde precisamente ao período da criação e intensificação das redes do tráfico de escravos e consequentemente, do relacionamento que se estabeleceu entre africanos e europeus, tendo como resultado o surgimento dos mestiços. Esse relacionamento reveste-se de suma importância dado que, é a partir do mesmo que surgirão, anos mais tarde, os denominados "filhos do país". Ainda neste primeiro capítulo, o autor apresenta as primeiras conotações produzidas na época em relação ao africano: "bárbaros, gentios, feitos para trabalhar, pura força de trabalho, pele negra" (p. 55), e que, de certa forma, irão orientar, em períodos distintos, e umas vezes mais do que outras, não só o relacionamento entre africanos e europeus e posteriormente também os mestiços, como igualmente toda a política colonial. 
E é em torno de toda essa dinâmica e da evolução dos acontecimentos que o autor nos apresenta, no segundo capítulo, as ideias em relação ao assunto, daquele que é considerado o "divulgador mais sofisticado do pensamento naturalista em Portugal" (p. I5I), - Oliveira Martins - realçando sobretudo o seu papel na sociedade e política portuguesa e a sua defesa pelas teses do darwinismo social, que, de acordo com o mesmo, deveria ser a base para a construção do tão ansiado Terceiro Império. Através dos discursos patrióticos e nacionalistas de Oliveira Martins, sobretudo no que toca à ideia de inferiorização do negro, entendido apenas como pura fonte de "força de trabalho" (p. 224), Barbeitos dá-nos a conhecer o lado menos popular daquele "vencido da vida" como o próprio denominou à toda a Geração de 70 da qual também fazia parte, acostumados que estamos a ler as suas obras sobre História de Portugal ou da Civilização Ibérica, entre outros. A sua posição contra a mistura de raças e contra os mestiços, vistos como "seres intermédios ou abastardados, às vezes monstros" (p. 240), contribuem para o processo de hierarquização dos seres humanos que, de uma maneira ou de outra, definirão não só os desígnios dos dois países, bem como a relação entre os dois povos, tendo reflexos ainda no presente.

Com uma posição diferente daquela adotada pela política colonial e pelos seus defensores mais fervorosos e entusiastas, o autor apresenta-nos Héli Chatelain, "uma das personalidades cristãs mais marcantes, senão a mais extraordinária, dos últimos anos de oitocentos e princípios do século XX" (p. 282). Defensor firme dos idiomas locais e crítico da política colonial portuguesa, este missionário protestante suíço é recordado como uma das figuras mais emblemáticas da história de Angola. A ele devemos um dos mais importantes e conhecidos estudos etnográficos sobre Angola, bem como a identificação e classificação dos grupos etnolinguísticos daquele país. Assim, enquanto o autor nos vai apresentando a sua biografia, vai igualmente traçando um paralelo com acontecimentos ocorridos em Angola, de modo que ficamos a conhecer o contexto encontrado pelo missionário aquando da sua chegada e instalação, bem como a evolução dos mesmos, o que nos permite não só conhecer melhor a pessoa que era, mas sobretudo o papel desempenhado pelas igrejas cristãs, com destaque para a Igreja protestante, na transformação sociocultural dos indígenas, que se tornaram mais eficazes que as ações do estado na produção e fixação de representações de si e de outrem.

E na produção destas representações o corpo assume uma importância primordial, ou seja, a tonalidade da cor da pele, bem como o processo anterior que deu origem a essa mesma 
cor. As diferentes conotações atribuídas à cor da pele constituem o tema principal deste quarto capítulo. $\mathrm{O}$ autor desenvolve assim um excelente debate teórico sobre a descoberta das raças, despertando um outro olhar sobre o corpo, na relação com o próprio corpo, ou seja, todo um discurso sobre a construção do conceito de raça e as diferentes conotações assumidas durante o período colonial - cafuso, cafrealizado, mulato - utilizadas para caracterizar todos os seres resultantes da mistura entre brancos e negros ao longo dos séculos. A análise desse capítulo permite-nos entender sobretudo a origem do protonacionalismo, do nacionalismo e posteriormente da criação dos movimentos nacionalistas e da sua luta pela independência, mas sobretudo, trata-se de entender como todo o pensamento e toda essa hierarquização se transformou igualmente em pressupostos sociais, como é o caso do "qualificativo cafuz (que) tinha entretanto obtido um valor muito mais social que racial" (p. 4I6).

O debate continua no quinto e último capítulo, que o autor inicia com uma contextualização histórica que nos permite entender a sociedade da época e consequentemente, a adoção de certas políticas. A ideia de construção de um novo Brasil em África, a consolidação do darwinismo social, e o assentamento de famílias portuguesas em Angola fazem do final do século XIX e da primeira metade do século XX o período por excelência da confirmação do espaço e da cultura angolana marcado pela violência física, moral e cultural do colonizador para com os colonizados, no caso, os africanos, e de certa forma, os mestiços. Neste capítulo o autor explora assim as diferentes facetas da exploração colonial, nomeadamente, o trabalho forçado, as roças de São Tomé, os serviçais, o consumo de álcool, até ao despertar dos primeiros nacionalistas, sem deixar de mencionar o papel preponderante dos mestiços na génese e formação destes nacionalistas uma vez que estes adquiriram uma "importância simbólica inestimável, pois por si passavam os múltiplos e complexos laços entre colonizadores e colonizados" (p. 559). E é precisamente nesta fase de consolidação da política colonial que as mestiçagens culturais mais se destacam, ao se unirem e se identificarem com uma cultura angolana, fruto da assimilação entre europeus e africanos, que reclamam pelo reconhecimento da sua identidade bem como o seu lugar na sociedade, empreendendo, para o efeito, diferentes manifestações de luta, que terminam somente com a independência daquele país, em 1975.

De destacar ainda a mensagem que a capa do livro nos transmite: duas máscaras que se diferenciam apenas pela cor: uma branca e uma preta. Porém, não vemos nenhuma máscara que representa a mistura das duas, precisamente porque essa mistura é mais do que 
simplesmente cromática. Há toda uma dinâmica resultante desse processo que deve e tem que ser entendida, ou seja, o "jogo equívoco das identidades" passa precisamente pela compreensão do resultado dessa mistura de dois mundos completamente diferentes, e que vão para além da existência dos mestiços, ou seja, há todo um processo de mestiçagem cultural que deve ser cuidadosamente analisado e compreendido.

Um dos grandes trunfos desta obra é sem dúvida a condensação de um período longo e complexo da história de Angola e de Portugal num único manual, onde os acontecimentos são descritos de forma ordenada, clara e simples, utilizando para o efeito uma linguagem descritiva e acessível. A complexidade do tema em si, aliada à fundamentação do autor impedem a sua leitura de um "sopro". Trata-se sim de uma obra académica, uma bíblia para os investigadores sobre a temática, um dos manuais mais importantes sobre a história de Angola e de Portugal, e que nos permite conhecer e melhor interpretar o presente, uma enciclopédia que deve estar sempre à mão para que se possa consultar quando necessário, mas sobretudo, trata-se de mais um contributo para a compreensão da temática em si e do relacionamento entre os dois povos, fornecendo igualmente pistas para a compreensão da realidade atual.

O manuseio da abundante informação e a solidez da argumentação apenas comprovam aquilo a que o autor já nos habituou - trabalho sério e bem fundamentado, revelador da sua competência e isso fica comprovado com o a vontade com que cruza diferentes escalas de análise, a interdisciplinaridade que transcende as fronteiras académicas, o seu distanciamento em relação ao objeto de estudo mesmo se tratando de um dos protagonistas da história de Angola, o que demonstra o domínio do corpus epistemológico e metodológico de cada disciplina, o manuseio brilhante de diferentes contextos, bem como a sua organização. Obviamente que a obra traz a público apenas uma pequena parte daquilo que Arlindo Barbeitos nos pode transmitir e ensinar. Ficamos a aguardar que nos continue a brindar com o seu excelente trabalho de qualidade, sobre esta ou outra temática. 